\title{
Economic evaluation of the breast cancer screening programme in the Basque Country: retrospective cost-effectiveness and budget impact analysis
}

Arantzazu Arrospide ${ }^{1,2,3^{*}}$, Montserrat Rue ${ }^{3,4}$, Nicolien T. van Ravesteyn ${ }^{5}$, Merce Comas ${ }^{3,6}$, Myriam Soto-Gordoa ${ }^{1}$, Garbiñe Sarriugarte ${ }^{7}$ and Javier Mar ${ }^{1,2,3,8}$

\begin{abstract}
Background: Breast cancer screening in the Basque Country has shown $20 \%$ reduction of the number of BC deaths and an acceptable overdiagnosis level ( $4 \%$ of screen detected BC). The aim of this study was to evaluate the breast cancer early detection programme in the Basque Country in terms of retrospective cost-effectiveness and budget impact from 1996 to 2011.

Methods: A discrete event simulation model was built to reproduce the natural history of breast cancer (BC). We estimated for lifetime follow-up the total cost of BC (screening, diagnosis and treatment), as well as quality-adjusted life years (QALY), for women invited to participate in the evaluated programme during the 15-year period in the actual screening scenario and in a hypothetical unscreened scenario. An incremental cost-effectiveness ratio was calculated with the use of aggregated costs. Besides, annual costs were considered for budget impact analysis. Both population level and single-cohort analysis were performed. A probabilistic sensitivity analysis was applied to assess the impact of parameters uncertainty.

Results: The actual screening programme involved a cost of 1,127 million euros and provided 6.7 million QALYs over the lifetime of the target population, resulting in a gain of 8,666 QALYs for an additional cost of 36.4 million euros, compared with the unscreened scenario. Thus, the incremental cost-effectiveness ratio was 4,214€/QALY. All the model runs in the probabilistic sensitivity analysis resulted in an incremental cost-effectiveness ratio lower than 10,000€/QALY. The screening programme involved an increase of the annual budget of the Basque Health Service by 5.2 million euros from year 2000 onwards.

Conclusions: The BC screening programme in the Basque Country proved to be cost-effective during the evaluated period and determined an affordable budget impact. These results confirm the epidemiological benefits related to the centralised screening system and support the continuation of the programme.
\end{abstract}

Keywords: Breast cancer, Screening, Cost-effectiveness, Budget impact analysis, Simulation, Modelling, Evaluation, Public health

\footnotetext{
* Correspondence: arantzazu.arrospideelgarresta@osakidetza.net

${ }^{1}$ Gipuzkoa AP-OSI Research Unit, Integrated Health Organization Alto Deba,

Avda Navarra 16, 20500 Arrasate-Mondragón, Gipuzkoa, Spain

${ }^{2}$ Aging and Chronicity Health Services Research Group, BIODONOSTIA

Research Institute, Paseo Dr Beguiristain s/n, 20014 Donostia, Gipuzkoa, Spain

Full list of author information is available at the end of the article
} 


\section{Background}

The evaluation of breast cancer (BC) screening is the subject of a controversial debate regarding its benefit and harms [1, 2]. The BC Screening Programme in the Basque Country (BCSPBC) invited more than 400,000 women from its start in 1996 through 2011 involving more than 1.3 million mammograms. Therefore a great annual investment was assigned in order to obtain future health benefit. During this period (1996-2011) the screening programme reduced $20 \%$ the number of $\mathrm{BC}$ deaths whereas $4 \%$ of screen detected $\mathrm{BC}$ were overdiagnosed, which has been found to be an acceptable level $[1,3]$. Although, these figures support the continuity of the programme, such a mass preventive intervention must be evaluated also in economic terms to warrant that the allocated resources are a worthwhile investment for the entire population [4].

As BC screening has been employed differently throughout the world [5], its evaluation needs to be fitted to the features of the actual women screened and to the implementation of the programme in reality. It is necessary to adopt a population-based approach in order to reflect all the demographic, epidemiological and clinical characteristics of the target population. In contrast with single cohort models, population-based models allow taking into account the heterogeneous composition of the population [6]. At the same time, this approach involves modelling the costs and benefits of all patients comprising both the cohort starting screening in the current year and those already undergoing screening from previous years [7]. Moreover, the interaction of population dynamics and heterogeneity, specially related to aging, could have a substantial effect on the final result of the evaluation [6, 8]. Although Markov modelling is the most common approach in cost-effectiveness analysis, discrete-event simulation models permit more flexible structures which allows including all these characteristics in a single model $[9,10]$. Using discrete-event simulation an artificial entity is created for each woman included in the BCSPBC and it is permitted to assign all kind of attributes to this entity in order to specify the evolution of that woman related to breast cancer and the correspondent effect of screening. By including the whole amount of entities that individually represent the invited women, the target population can be reproduced. Allowing multi-cohort modelling is a key advantage of discrete-event simulation in order to carry out economic evaluation of public health programmes.

In the context of the BCSPBC, we can retrospectively examine the cost and effectiveness for the period 1996 through 2011. Recently, a simulation model was developed with the aim of estimating the effect of the BCSPBC mainly in terms of BC mortality decrease and overdiagnosed cases [3]. We have used the same model, already calibrated and validated, to estimate overall costs and quality adjusted life years (QALY) attributable to the screening programme. Additional information in terms of budget impact analysis will help decision-makers to fully understand the economic impact of the screening programme on the budget of the Basque health system. Cost-effectiveness analysis and budget impact analysis provide complementary information and both are necessary when a large volume of the population is involved in the assessed intervention [11].

The aim of this study was to carry out the evaluation of the $\mathrm{BC}$ early detection programme in the Basque Country in terms of cost-effectiveness and budget impact from 1996 to 2011.

\section{Methods}

A discrete event simulation model $[9,10]$ was built to reproduce the natural history of $\mathrm{BC}$ according to the key characteristics of the female population invited into the programme from its beginning in 1996 through 2011 [3]. The screening test for BCSPBC consisted of mammography with double projection carried out biennially on all women aged 50 to 69 years. The target population comprised multiple cohorts of women; not only women who were invited to the programme for the first time but also successive invitations for those already included in the BCSPBC $[7,12]$, thus a multiple-cohort model (dynamic model) was used to represent the whole population including women invited in different calendar years. The model allowed lifetime follow-up for each woman invited to the programme to measure both the long-term costs and benefits of screening. The evaluation period was defined as 1996 through December 31, 2011 , as the target population of the programme was changed during 2012 and extended to women in their 40 's with a first-degree family history of BC. However, the simulation model allowed lifetime follow-up in order to estimate the future effects of the screening during the evaluated period. The Ethics Committee for Clinical Research in Gipuzkoa Health Area evaluated and approved the study.

\section{Model overview}

We modelled the natural history of $\mathrm{BC}$ using the approach of Lee et al. [13]. Four main states of health were distinguished: (1) disease-free or undetectable BC; (2) asymptomatic $\mathrm{BC}$ that could be diagnosed by screening; (3) symptomatic BC diagnosed clinically; and (4) death from BC. Time-to-event distributions used for the modelling of the natural history of $\mathrm{BC}$ were obtained from previous studies [13-15]. All-cause mortality, excluding breast cancer specific mortality was also included as a competing risk [16]. 
Other model input data, such as the exact number of women invited for the first time and their age at the first invitation, programme sensitivity and specificity, the number of positive mammography results and the additional diagnostic tests carried out, and age- and stagespecific cancer incidence were obtained from the BCSPBC database. The final model was calibrated to obtain the closest possible results to observed data. A full description of the model has already been published [3], however a Methodology Appendix (Additional file 1) which describes the main model details and contains a simplified diagram of the model is also available online.

\section{Utilities}

Due to the lack of quality of life estimations in women affected by $\mathrm{BC}$ we decided to apply the methodology described by Stout et al to estimate the age-specific quality-of-life utility weights for the different health states [17]. The first step consisted of obtaining agespecific EuroQol EQ-5D quality-of-life utility weights for general Spanish women population [18]. Following the aforementioned approach, specific percentages were applied to general population utilities in order to estimate the potential negative effects of a $\mathrm{BC}$ diagnosis during the first year of treatment and end of life (Table 1). We considered end of life equivalent to the metastatic stage in terms of quality of life and duration.

\section{Costs}

The perspective of the Basque National Health Service was considered for the economic evaluation. We included both BC diagnosis (screening and additional diagnosis tests) and treatment costs (initial, follow-up and end of life), based on resource consumption and unit costs of the Basque Health Services. The methodology of calculating the unitary costs is fully described elsewhere by Arrospide et al. [19].

The diagnostic costs included screening mammography $(42.28 €)$ and other diagnostic tests carried out in the reference hospital such as echography $(44.14 €)$, fine needle aspiration (113.49€), core needle biopsy (127.46€) and surgical biopsy $(2,594 €)$. Attendants were classified in 5 groups according to screening mammography evidence for $\mathrm{BC}$. Women in the highest groups (3 to 5)

Table 1 Quality of life weights in Spanish women population and its reduction due to breast cancer detection

\begin{tabular}{lllll}
\hline & Health state & & \\
\cline { 2 - 5 } Age & Healthy [18] & In Situ or Stage I & Stage II or III & Stage IV \\
\hline $50-64$ & 0.824 & 0.742 & 0.618 & 0.495 \\
$65-74$ & 0.770 & 0.693 & 0.578 & 0.462 \\
$75-84$ & 0.682 & 0.614 & 0.512 & 0.409 \\
$>84$ & 0.563 & 0.507 & 0.422 & 0.338 \\
\hline
\end{tabular}

were assigned additional tests, one or several, according to the probability observed in the programme data base for the correspondent evidence group.

Treatment costs for $\mathrm{BC}$ detected in a clinical stage other than IV were divided into initial and 5-year follow-up costs. When $\mathrm{BC}$ was the cause of death, we incorporated the increased costs of the last year of life using the cost of metastatic stage. Initial treatment costs included surgery, radiotherapy and chemotherapy. Pharmacological treatment and medical consultations were incorporated in follow-up costs. For cases of metastatic BC, only annual follow-up costs were calculated. The initial cost was $9.838 €$ for stage $0,17.273$ for I, 22.145 for II, and 28.776 for III. The follow-up annual cost was $172 €$ for stage 0,908 for 1,994 for II, and 1,166 for III. The annual cost for stage IV was $17,879 €$.

\section{Cost-effectiveness analysis}

Two identical populations were created and followed until death to estimate lifetime costs and QALYs in the screened and unscreened populations. Women in the screened arm were invited according to BCSPBC implementation and no screening mammography was simulated from year 2011 onwards. However, lifetime time horizon was applied to the model to include long-term screening effects. According to the approach applied by Stout et al, during this 15-year period (retrospective time), neither costs nor QALYs were discounted, and a $3 \%$ annual discount rate was applied prospectively to both costs and QALYs, beginning from the end of the evaluated period (31st December 2011) until death $[17,20]$. In addition, a complementary scenario with no discount (0 \% discount) applied was also considered.

The same model was employed to calculate the ICER for the case of a single cohort of 50,000 women aged 50 years invited to join the programme for the first time in 1996. We used the same alternatives as in the population level approach (with and without screening). As cost-effectiveness analysis is generally applied for a single cohort, these complementary results permit comparison with published data.

\section{Probabilistic sensitivity analysis}

The probabilistic feature of the model was based on varying the main variables randomly at the same time [21]. Each variable was assigned a distribution fitting the range of all possible values and at the beginning of each simulation a random generator selected the value for each variable from the specified distribution. This permitted to examine the effect of joint uncertainty in the variables of the model through cost-effectiveness plane and acceptability curve [21]. The cost-effectiveness plane displays the incremental cost (vertical axis) and effectiveness (horizontal axis) results of 1,000 simulation runs 
(Fig. 1). The mean value and $95 \%$ confidence intervals (CI) were shown for the total costs and QALYs, for the differences between the results for the two scenarios, and for the ICER. The distributions used for the main parameters varied in the probabilistic sensitivity analysis were detailed in the Methodology Appendix (Additional file 1).

Variability in participation rates was not included in the main probabilistic sensitivity analysis as variability was assumed very small. However, as we were concerned about the interest on the variation of this parameter we ran cost-effectiveness analysis for the main single-cohort model in two more scenarios with lower participation rates: 50 and $30 \%$.

\section{Budget impact analysis}

The simulation model built for multi-cohort costeffectiveness analysis was used simultaneously for budget impact analysis. Cost-effectiveness analysis allows estimating the additional benefit of a new treatment in relationship with its cost and permit comparing the results to those obtained for already accepted treatments. Undoubtedly, the framework described for costeffectiveness analysis is accepted by experts panels all over the world $[8,22]$. However there are some doubts about its real application when health services management is based on a fixed budget. Budget impact analysis provides a new tool to estimate the effect of the decision hold on the future budget of the health services. As defined by Mauskopf et al. budget impact analysis assesses the impact of a new intervention in annual costs, annual health benefits and other important outcomes from its implementation onwards [11, 23].

The model was developed to calculate the annual costs for $\mathrm{BC}$ diagnosis and treatment in both the screened and unscreened populations. Diagnostic resources included screening or symptomatic mammograms, as well as other additional diagnostic tests that were implemented in the reference hospital. Treatment costs involved the initial treatment of the $\mathrm{BC}$ detected each year and follow-up therapy for prevalent $\mathrm{BC}$, as well as end-of-life costs for those who died from $\mathrm{BC}$. As the budget impact analysis presented financial streams over time, it was not necessary to discount the costs [11].

\section{Results}

The results of the population-level cost-effectiveness analysis are shown in Table 2. The 15-year evaluation demonstrated a cost of 1,126.6 million euros $(1,608.7$ million euros, undiscounted) and a provision of 6.70

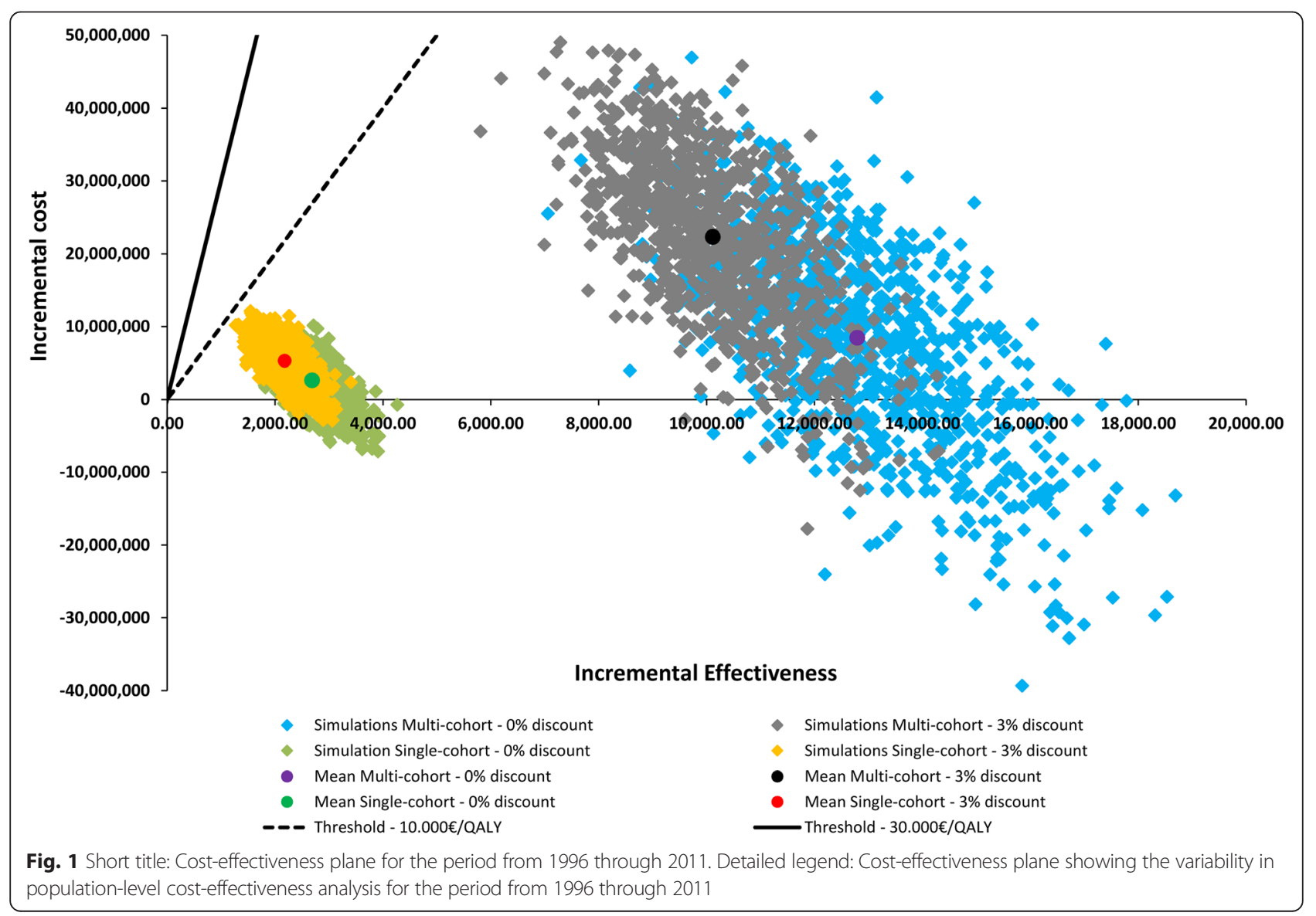


Table 2 Cost-effectiveness analysis of breast cancer screening using the multi-cohort (population level) approach

\begin{tabular}{|c|c|c|c|c|c|c|}
\hline & \multicolumn{3}{|c|}{$0 \%$ discount $^{\mathrm{a}}$} & \multicolumn{3}{|c|}{$3 \%$ discount $^{a}$} \\
\hline & Mean & \multicolumn{2}{|l|}{$95 \% \mathrm{Cl}$} & Mean & \multicolumn{2}{|l|}{$95 \% \mathrm{Cl}$} \\
\hline \multicolumn{7}{|l|}{ Screened population } \\
\hline Total costs (Million Euros) & $1,608.7$ & $1,566.0$ & $1,651.7$ & $1,126.6$ & $1,097.8$ & $1,155.3$ \\
\hline Screening mammography costs & 55.3 & 55.2 & 55.5 & 55.3 & 55.2 & 55.5 \\
\hline Screening diagnosis workup & 12.1 & 11.5 & 12.7 & 12.1 & 11.5 & 12.7 \\
\hline Clinical cancers diagnosis workup & 26.1 & 25.2 & 27.0 & 18.3 & 17.6 & 18.9 \\
\hline Treatment costs & $1,515.1$ & $1,472.8$ & $1,557.5$ & $1,040.9$ & $1,012.5$ & $1,069.3$ \\
\hline QALYS & $8,845,493$ & $8,828,791$ & $8,862,195$ & $6,696,959$ & $6,684,899$ & $6,709,019$ \\
\hline \multicolumn{7}{|l|}{ Unscreened population } \\
\hline Total costs (Million Euros) & $1,584.3$ & $1,538.8$ & $1,629.8$ & $1,090.2$ & $1,059.2$ & $1,121.3$ \\
\hline Screening mammography costs & 0.00 & 0.00 & 0.00 & 0.0 & 0.0 & 0.0 \\
\hline Screening diagnosis workup & 0.00 & 0.00 & 0.00 & 0.0 & 0.0 & 0.0 \\
\hline Clinical cancers diagnosis workup & 30.2 & 29.2 & 31.11 & 22.2 & 21.5 & 22.9 \\
\hline Treatment costs & $1,554.1$ & $1,509.0$ & $1,599.24$ & $1,068.0$ & $1,037.3$ & $1,098.8$ \\
\hline QALYS & $8,834,785$ & $8,818,066$ & $8,851,504$ & $6,688,293$ & $6,676,240$ & $6,700,347$ \\
\hline \multicolumn{7}{|l|}{ Difference (Screened - Unscreened) } \\
\hline Total costs (Million Euros) & 24.4 & 8.5 & 40.3 & 36.4 & 24.6 & $1,557.5$ \\
\hline Screening mammography costs & 55.3 & 55.2 & 55.5 & 55.3 & 55.2 & 55.5 \\
\hline Screening diagnosis workup & 12.1 & 11.5 & 12.7 & 12.1 & 11.5 & 12.7 \\
\hline Clinical cancers diagnosis workup & -4.0 & -5.1 & -2.9 & -3.9 & -4.8 & -3.1 \\
\hline Treatment costs & -39.0 & -54.8 & -23.1 & -27.1 & -38.9 & -15.4 \\
\hline QALYS & 10,708 & 9,499 & 11,917 & 8,666 & 7,746 & 9,586 \\
\hline ICER & 2,294 & 738 & 3,850 & 4,214 & $2,703.41$ & 5,725 \\
\hline
\end{tabular}

Cl confidence interval, QALY quality-adjusted life years, ICER incremental cost-effectiveness ratio

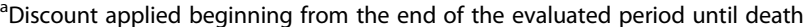

million QALYs (8.84 million QALYs, undiscounted) for lifetime follow-up. In the non-screened scenario, these values were reduced to $1,090.2$ million euros and 6.69 million QALYs. Thus, the ICER was $4,214 €$ per QALY (2,294€/QALY, undiscounted). When disaggregated costs are analysed, $92 \%$ of the total costs were attributed to $\mathrm{BC}$ treatment in the screened population. Over the entire study period more than 55 million euros were invested in BC screening mammography, with an additional 12 million for further diagnostic tests, whereas only four million euros were saved in clinical or symptomatic diagnosis. Early detection also involved a savings of more than 27 million euros in the treatment of $\mathrm{BC}$ detected in the evaluated population. When a usual single-cohort cost-effectiveness analysis was carried out, the final results were similar in terms of ICER (Table 3).

Incremental costs and incremental effectiveness in each of the 1,000 simulations carried out in probabilistic sensitivity analysis are shown graphically in Fig. 1. All the simulations resulted in an ICER lower than $10,000 €$ per QALY. In addition, the related acceptability curve
(Methodology Appendix) showed that in $3 \%$ of the simulations screening was dominant (saved costs) both for the single-cohort and multiple-cohort models when no discount was applied. However, this percentage increased up to $21 \%$ for the single-cohort model and $27 \%$ with population level approach when costs and QALYs were discounted (3\% discount). On the other hand, incremental costs and effectiveness proportionally decreased when lower participation rates were applied in the single-cohort model, therefore the incremental costeffectiveness ratio result similar in the three scenarios (Table 4).

Annual total costs for budget impact analysis are shown in Fig. 2. In 2011, more than 36 million euros were necessary to continue with the $\mathrm{BCSPBC}$ and the treatment costs related to previously detected $\mathrm{BC}$; this estimation is growing yearly. As a consequence of the implementation of the screening programme, it had been necessary to add up to 9.2 million euros to the budget of the Basque Health Service in 1998. However, this figure became relatively stable from year 2000 onwards in annual 5.2 million euros. 
Table 3 Cost-effectiveness analysis of breast cancer screening using a single cohort

\begin{tabular}{|c|c|c|c|c|c|c|}
\hline & \multicolumn{3}{|c|}{$0 \%$ discount $^{\mathrm{a}}$} & \multicolumn{3}{|c|}{$3 \%$ discount $^{a}$} \\
\hline & Mean & $95 \% \mathrm{Cl}$ & & Mean & $95 \% \mathrm{Cl}$ & \\
\hline \multicolumn{7}{|l|}{ Screened population } \\
\hline Total costs (Million Euros) & 213.0 & 204.7 & 221.3 & 161.9 & 155.9 & 167.8 \\
\hline Screening mammography costs & 12.5 & 12.458 & 12.5 & 12.5 & 12.5 & 12.5 \\
\hline Screening diagnosis workup & 2.9 & 2.7 & 3.1 & 2.9 & 2.8 & 3.1 \\
\hline Clinical cancers diagnosis workup & 3.0 & 2.9 & 3.2 & 2.2 & 2.1 & 2.3 \\
\hline Treatment costs & 194.5 & 186.3 & 202.8 & 144.2 & 138.3 & 150.1 \\
\hline QALYS & $1,231,858$ & $1,228,748$ & $1,234,968$ & 997,681 & 995,195 & $1,000,168$ \\
\hline \multicolumn{7}{|l|}{ Non-screened population } \\
\hline Total costs (Million Euros) & 206.7 & 197.4 & 216.0 & 153.2 & 146.5 & 160.0 \\
\hline Screening mammography costs & 0.0 & 0.0 & 0.0 & 0.0 & 0.0 & 0.0 \\
\hline Screening diagnosis workup & 0.0 & 0.0 & 0.0 & 0.0 & 0.0 & 0.0 \\
\hline Clinical cancers diagnosis workup & 3.9 & 3.7 & 4.1 & 3.1 & 2.9 & 3.2 \\
\hline Treatment costs & 202.8 & 193.6 & 212.1 & 150.2 & 143.5 & 156.9 \\
\hline QALYS & $1,229,578$ & $1,226,441$ & $1,232,715$ & 995,803 & 993,304 & 998,301 \\
\hline \multicolumn{7}{|l|}{ Difference (Screened - Unscreened) } \\
\hline Total costs (Million Euros) & 6.3 & 2.5 & 10.1 & 8.6 & 5.7 & 202.8 \\
\hline Screening mammography costs & 12.5 & 12.5 & 12.5 & 12.5 & 12.5 & 12.5 \\
\hline Screening diagnosis workup & 2.9 & 2.7 & 3.1 & 2.9 & 2.8 & 3.1 \\
\hline Clinical cancers diagnosis workup & -0.9 & -1.1 & -0.7 & -0.9 & -1.0 & -0.7 \\
\hline Treatment costs & -8.3 & -12.1 & -4.5 & -6.0 & -8.9 & -3.0 \\
\hline QALYS & 2,280 & 1,986 & 2,575 & 1,879 & 1,650 & 2,108 \\
\hline ICER & 2,778 & 974 & 4,582 & 4,623 & 2,830 & 6,416 \\
\hline
\end{tabular}

Cl confidence interval, QALY quality-adjusted life years, ICER incremental cost-effectiveness ratio

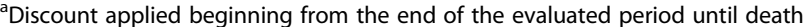

\section{Discussion}

The $\mathrm{BC}$ screening programme in the Basque Country proved cost-effective during the evaluation period with both multi-cohort and single-cohort approaches assuming the recommended threshold of 30,000€ per QALY [24]. When a $3 \%$ discount was applied to costs and

Table 4 Cost-effectiveness analysis for a single cohort in different attendance rate scenarios

\begin{tabular}{llll}
\hline Participation rate & $\begin{array}{l}\text { Incremental costs } \\
\text { (Million Euros) }\end{array}$ & $\begin{array}{l}\text { Incremental } \\
\text { effectivenes (QALYs) }\end{array}$ & ICER \\
\hline $0 \%$ discount & & 2,280 & 2,778 \\
Base Case & 6.3 & 1,715 & 1,888 \\
$50 \%$ attendance & 3.2 & 1,136 & 1,453 \\
$30 \%$ attendance & 1.7 & & 4,623 \\
$3 \%$ discount ${ }^{a}$ & & 1,879 & 3,601 \\
Base Case & 8.6 & 1,409 & 3,051 \\
$50 \%$ attendance & 5.1 & 934 & \\
$30 \%$ attendance & 2.9 &
\end{tabular}

QALY quality-adjusted life years, ICER incremental cost-effectiveness ratio

${ }^{a}$ Discount applied beginning from the end of the evaluated period until death utilities from 2011 on, the ICER increased slightly but it was still far below the established threshold. The simultaneous use of a combined and a single-cohort approach was helpful to compare the efficiency of $\mathrm{BC}$ screening in real population dynamics (multi-cohort model) and incident cohort (single-cohort). In both cases, the results are valid only if the follow-up is long enough to achieve a steady state in the interaction between the natural history of $\mathrm{BC}$ and all its determinants that are modified by the screening. The steady state is defined as the time when each recently observed behaviour of the system (trade-off between short-term costs and long-term benefits) will remain constant in the future [25].

In a comparison of different screening programmes, De Koning pointed out the dependence of the costeffectiveness on the attendance rate and the quality of the programme [5]. Thus, this ICER is within the range of the best programmes as the high participation rate $(80 \%)$ and other quality indicators of the Basque programme fit well the recommended guidelines [26, 27]. As noted in the literature, some of those favourable figures are related to the centralised system applied by the Basque Health 


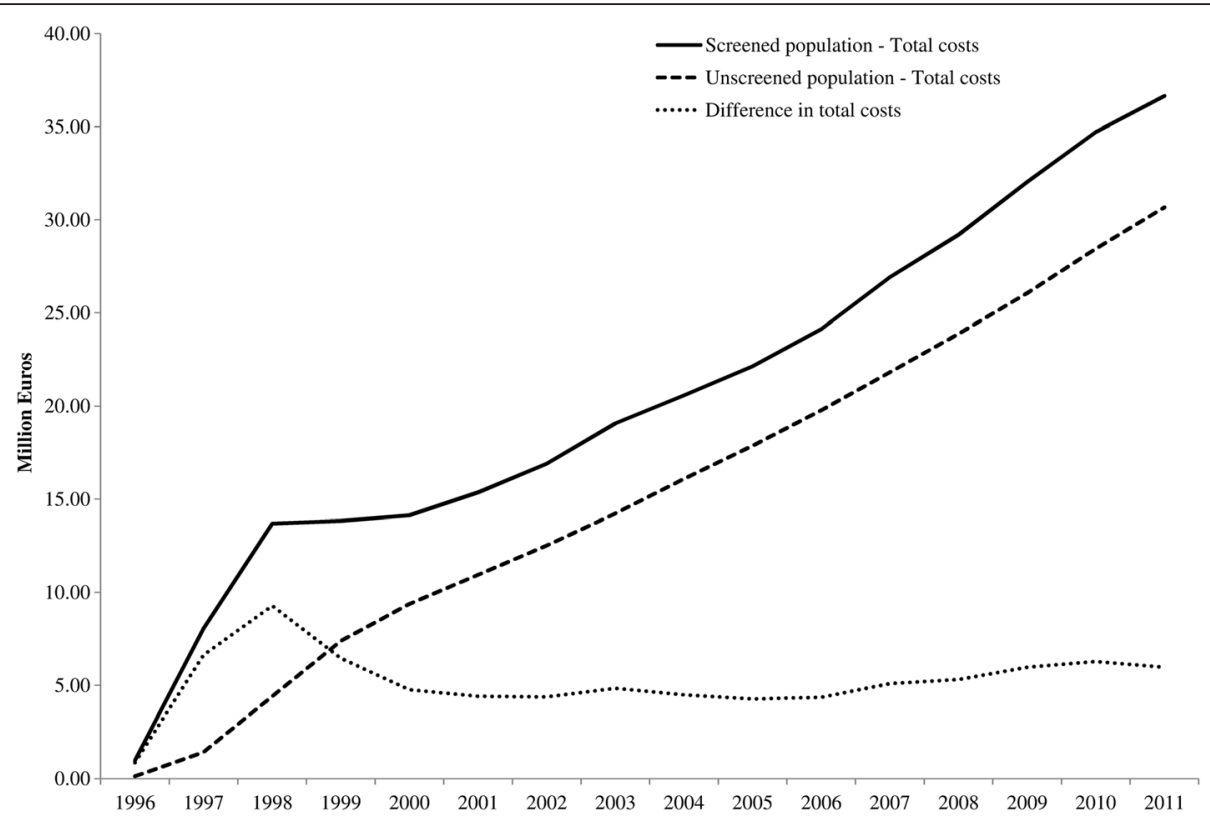

Fig. 2 Short title: Budget impact analysis for the period from 1996 through 2011. Detailed legend: Budget impact analysis for the period from 1996 through 2011 for the scenarios with and without screening

Service to implement the BCSPBC [5]. Our results are similar to other studies carried out in the Spanish context that used ordinary, single-cohort cost-effectiveness analysis. Carles et al. obtained an ICER of 4,469€/QALY [28] in Catalonia. The MIcrosimulation SCreening ANalysis (MISCAN) model was developed in the 1980's to evaluate the effects of breast cancer screening in the Netherlands [29] and applied to Navarra [30] resulted in an ICER of 2,650€/life-year gained (LYG), whereas, when the MISCAN model was applied to Catalonia, it resulted in 4,475 $€ /$ LYG [31]. Interestingly, application of the MISCAN model in the Netherlands with the same strategy (women aged 50-70 invited every 2 years) resulted in a similar ICER $(3,400 € / Q A L Y)$ [32].

Current guidelines for health economic evaluation and modelling have not adequately addressed the issue of cohort definition [33]. Although the standard approach is to use a single cohort, different authors have underlined the advantages of a multi-cohort method to reproduce real-world populations [7, 34]. Kuntz et al. [33] noted that if no substantial heterogeneity is found on the basis of characteristics of the screened women in the prevalent and incident cohorts, both approaches render similar results [33] and our results are in line with this affirmation. Similarly, O'Mahony et al. [12] highlighted how the ICER is influenced by the number of birth cohorts under differential discounting [34]. As we have used the same discounting, aggregating cohorts did not produce differences.

All investment decisions involve an opportunity cost, and therefore, a decision to spend on one option deprives the beneficiaries of another option [8]. Thus, investment in health care, curative and public health requires evidence of effectiveness and cost-effectiveness of competing interventions [35]. When we take into account both the 67.4 million euros invested in the screening programme during its first 15 years and the total cost of roughly 1,000 million euros (36 million euros in excess), it seems clear that an explicit statement is needed regarding the best use of those resources. Actually, due to the increase in $\mathrm{BC}$ incidence and longer survival times achieved by early detection, an increase in the prevalence of treated cancers occurred and thus, overall costs increased considerably. In addition, treatment costs would have continued, even if the screening programme had stopped in 2011. The complementary budget impact analysis showed how the overall annual costs varied in the first years of implementation and the difference between scenarios stabilized after 2000 at approximately five million euros. The small increase in 2007 is the result of the increased screening age of 70 years. The overall diagnosis and treatment cost of the $\mathrm{BC}$ for the women included in the programme in the Basque Country increased to 36.6 million euros in 2011.

The high attendance rate for the programme helped to reduce disparities in $\mathrm{BC}$ survival $[36,37]$. Screening rejection has been proposed on the supposition that new cutting-edge treatments can offset the delay in diagnosis, thus, making it unnecessary to treat at an earlier stage [2]. This theory has not yet been confirmed, and, even if established, such an approach would not guarantee that innovative therapies would be available to all women 
with $\mathrm{BC}$. On the contrary, high attendance rates in screening programmes means that the benefit now reaches every female subject in the programme without considering her socioeconomic level.

The retrospective nature of the design of this study posed some doubts about how to deal with discounting $[8,12,17,33]$. Following the method of Stout et al, we discounted only the future costs and benefits [17]. In other words, the results (costs and QALYs) during the evaluation period (1996 to 2011) were directly aggregated, because they had already occurred, but we did discount the follow-up of women living after 2012 to their death as future costs and included QALYs. Although the ICER calculated without any discount changed from 4,214 to 2,294€ per QALY, the difference was not significant, because both figures were far below the usual threshold $(30,000 € /$ QALY). Similarly, from both single-cohort and multi-cohort models, we obtained almost the same ICER (4,600 and 4,200€/QALY), which underlines the efficiency of the programme.

The growing budget impact indicates that during these years women included in the programme progressively represented a larger portion of the treatment costs of BC. The more years of follow-up included in the programme, the closer the budget is to arriving at a plateau, as these figures include only screened women. These figures highlight that after 15 years of screening the difference between budgets in the two scenarios (screened and unscreened population) could still vary in the future.

\section{Conclusions}

Our economic results confirm the epidemiological benefits related to the centralised screening system and support, first, the continuation of the programme and, second, the long follow-up required to fully evaluate the benefit of the programme. In terms of cost-effectiveness the ICER obtained in both population level evaluation and single-cohort assessment were far below the threshold used for decision making. However, in order to make the final decision it is necessary to take into account that five million Euros more were required annually in average in the budget of the Basque Health Services due to the implementation of the screening programme.

\section{Additional file}

Additional file 1: Model description. This file includes 465 the detailed description of the simulation model built for 4667 this study. (PDF 429 kb)

\section{Abbreviatons}

$\mathrm{BC}$, breast cancer; $\mathrm{BCSPBC}$, breast cancer screening programme in the Basque Country; Cl, confidence interval; ICER, incremental cost-effectiveness ratio; LYG, life years gained; MISCAN, microsimulation screening analysis; QALY, quality adjusted life years.

\section{Acknowledgements}

We would like to acknowledge the support from Ester Vilaprinyó in the competing risks analysis and the natural history of breast cancer model We also want to thank Sally Ebeling for editorial assistance. Finally, we thank the Basque Cancer Registries for providing breast cancer incidence data and the Basque Mortality Registry for providing mortality data.

\section{Funding}

This study was funded by the grant 2010111007 from the Health

Department of the Basque Government.

\section{Availability of data and materials}

The dataset(s) supporting the conclusions or this article are included within the article and the Additional file 1.

\section{Authors' contribution}

Study concept and design: AA, JM, MR, MC, MS. Acquisition of data: MR, GS, JM. Model construction and validation: AA, MR, NvR, MC. Statistical analysis and interpretation of the results: $A A, M S, M R$, NVR. Drafting of the manuscript: AA, JM. Critical revision of the manuscript: MR, NvR, MC, MS, GS. All the authors have read and approved the final version of the manuscript.

\section{Competing interests}

The authors declare that they have no competing interests.

\section{Consent for publication}

Not applicable.

Ethics approval and consent to participate

Not applicable.

\section{Author details}

${ }^{1}$ Gipuzkoa AP-OSI Research Unit, Integrated Health Organization Alto Deba, Avda Navarra 16, 20500 Arrasate-Mondragón, Gipuzkoa, Spain. ²Aging and Chronicity Health Services Research Group, BIODONOSTIA Research Institute, Paseo Dr Beguiristain s/n, 20014 Donostia, Gipuzkoa, Spain. ${ }^{3}$ REDISSEC (Red de Investigación en Servicios de Salud en Enfermedades Crónicas - Spanish Health Services Research on Chronic Patients Network), Bilbao, Bizkaia, Spain. ${ }^{4}$ Basic Medical Sciences department, Biomedical Research Institute of Lleida, University of Lleida, Avda. Rovira Roure 80, 25198 Lleida, Spain. ${ }^{5}$ Department of Public Health, Erasmus University Medical Center Rotterdam, Dr

Molewaterplein 50, 3015, GE, Rotterdam, The Netherlands. ${ }^{6}$ Evaluation and Epidemiology Department, Hospital del Mar - IMIM (Hospital del Mar Medical Research Institute), Passeig Maritim 25-29, 08003 Barcelona, Spain. ${ }^{7}$ Breast Cancer Early Detection Programme, Public Health Division of Bizkaia, Basque Government, Alameda Rekalde 39, 48008 Bilbao, Bizkaia, Spain. ${ }^{8}$ Health Management Service, Integrated Health Organization Alto Deba, Avda Navarra 16, 20500 Arrasate-Mondragón, Gipuzkoa, Spain.

Received: 17 September 2015 Accepted: 25 May 2016

Published online: 01 June 2016

\section{References}

1. Paci E. EUROSCREEN Working Group. Summary of the evidence of breast cancer service screening outcomes in Europe and first estimate of the benefit and harm balance sheet. J Med Screen. 2012;19 Suppl 1:5-13.

2. Biller-Andorno N, Jüni P. Abolishing mammography screening programmes? A view from the Swiss Medical Board. N Engl J Med. 2014;370:1965-7.

3. Arrospide A, Rue M, van Ravesteyn NT, Comas M, Larrañaga N, Sarriugarte G, Mar J. Evaluation of health benefits and harms of the breast cancer screening programme in the Basque Country. BMC Cancer. 2015;15:671.

4. Russell LB, Gold MR, Siegel JE, Daniels N, Weinstein MC. The role of costeffectiveness analysis in health and medicine. JAMA. 1996;276:1172-7.

5. De Koning HJ. Breast cancer screening; cost-effective in practice? Eur J Radiol. 2000:33:32-7.

6. $\quad$ Ethgen $\mathrm{O}$, Standaert B. Population- versus cohort-based modelling approaches. Pharmacoeconomics. 2012;30:171-81.

7. Hoyle M, Anderson R. Whose costs and benefits? Why economic evaluations should simulate both prevalent and all future incident patient cohorts. Med Decis Making. 2010;30:426-37. 
8. Gold M, Siegel J, Russell L, editors. Cost-effectiveness in health and medicine. New York: Oxford University Press; 1996.

9. Karnon J, Stahl J, Brennan A, Caro JJ, Mar J, Möller J. Modeling using discrete event simulation: a report of the ISPOR-SMDM Modeling Good Research Practices Task Force-4. Med Decis Making. 2012;32:701-11.

10. Stahl JE. Modelling methods for pharmacoeconomics and health. Pharmacoeconomics. 2008;26:131-48.

11. Sullivan SD, Mauskopf JA, Augustovski F, Jaime Caro J, Lee KM, Minchin M, Orlewska E, Penna P, Rodriguez Barrios JM, Shau WY. Budget impact analysis-principles of good practice: report of the ISPOR 2012 Budget Impact Analysis Good Practice II Task Force. Value Health. 2014;17:5-14.

12. O'Mahony JF, van Rosmalen J, Zauber AG, van Ballegoijen M. Multicohort models in cost-effectiveness analysis: why aggregating estimates over multiple cohorts can hide useful information. Med Decis Making. 2013;33: 407-14

13. Lee $\mathrm{S}$, Zelen M. A stochastic model for predicting the mortality of breast cancer. J Natl Cancer Inst Monogr. 2006;36:79-86.

14. Rue M, Vilaprinyo E, Lee S, Martinez-Alonso M, Carles MD, Marcos-Gragera R, Pla R, Espinas JA. Effectiveness of early detection on breast cancer mortality reduction in Catalonia (Spain). BMC Cancer. 2009;9:326-35.

15. Vilaprinyo E, Rue M, Marcos-Gragera R, Martinez-Alonso M. Estimation of age- and stage-specific Catalan breast cancer survival functions using US and Catalan survival data. BMC Cancer. 2009;9:98-111.

16. Vilaprinyo E, Gispert R, Martínez-Alonso M, Carles M, Pla R, Espinàs JA, Rué M. Competing risks to breast cancer mortality in Catalonia. BMC Cancer. 2008:8:331-8.

17. Stout NK, Rosenberg MA, Trentham-Dietz A, Smith MA, Robinson SM, Fryback DG. Retrospective cost-effectiveness analysis of screening mammography. J Natl Cancer Inst. 2006;98:774-82.

18. Oliva-Moreno J, Lopez-Bastida J, Worbes-Cerezo M, Serrano-Aguilar P. Health related quality of life of Canary Island citizens. BMC Public Health. 2010;10:675.

19. Arrospide A, Soto-Gordoa M, Acaiturri T, Lopez-Vivanco G, Abecia LC, Mar J. Coste del tratamiento del cancer de mama por estadío clínico en el País Vasco. Rev Esp Salud Pública. 2015;89:1-5.

20. National Institute for Health and Care Excellence (NICE). Guide to the methods of technology appraisal 2013. London. 2013. Available in: http://www.nice.org.uk/article/pmg9/resources/non-guidance-guide-tothe-methods-of-technology-appraisal-2013-pdf. Accessed 29 Dec 2014.

21. Briggs $\mathrm{A}$, Schulpher $\mathrm{M}$, Claxton $\mathrm{K}$. Decision modelling for health economic evaluation. New York: Oxford University Press; 2006.

22. Lopez-Bastida J, Oliva J, Antoñanzas F, García-Altés A, Gisbert R, Mar J, Puig-Junoy J. Spanish recommendations on economic evaluation of health technologies. Eur J Health Econ. 2010;11:513-20.

23. Mauskopf J, Earnshaw S, Mullins CD. Budget impact analysis: review of the state of art. Expert Rew Pharmacoeconomics Outcomes Res. 2005;5:65-79.

24. Sacristan JA, Oliva J, del Llano J, Prieto L, Pinto JL. ¿Qué es una tecnología sanitaria eficiente en España? Gac Sanit. 2002;4:334-43.

25. Asmussen S, Glynn PW. Stochastic Simulation: Algorithms and Analysis. Series Stochastic Modelling and Applied Probability. New York: Springer Edits; 2007. p. 57.

26. Del Turco MR, Ponti A, Bick U, Biganzoli L, Cserni G, Cutuli B, Decker T, Dietel $\mathrm{M}$, Gentilini $\mathrm{O}$, et al. Quality indicators in breast cancer care. Eur J Cancer. 2010;46:2344-56.

27. Canadian Partnership Against Cancer. Report from the Evaluation Indicators Working Group: Guidelines for Monitoring Breast Cancer Screening Programme Performance. 3rd ed. Toronto: Canadian Partnership Against Cancer; 2013.

28. Carles M, Vilaprinyo E, Cots F, Gregori A, Pla R, Román R, Sala M, Macià F, Castells X, Rue M. Cost-effectiveness of early detection of breast cancer in Catalonia (Spain). BMC Cancer. 2011;11:192-203.

29. Habbema JD, van Oortmarssen GJ, Lubbe JT, van der Maas PJ. Model building on the basis of Dutch cervical cancer screening data. Maturitas. 1985;7:11-20.

30. Van den Akker-van Marle ME, Reep-van den Bergh CM, Boer R, Del Moral A, Ascunce $\mathrm{N}$, de Koning $\mathrm{HJ}$. Breast cancer screening in Navarra: interpretation of a high detection rate at the first screening round and a low rate at the second round. Int J Cancer. 1997;73:464-9.

31. Beemsterboer PMM, Warmerdam PG, Boer R, Borras JM, Moreno V, Viladiu P, de Koning HJ. Screening for breast cancer in Catalonia. Which policy is to be preferred? Eur J Public Health. 1998;8:241-6.
32. De Koning HJ, van Ineveld BM, van Oortmarssen GJ, de Haes JCJM, Collette HJA, Hendriks JHCL, van der Maas PJ. Breast cancer screening and costeffectiveness; policy alternatives, quality of life considerations and the possible impact of uncertain factors. Int J Cancer. 1991;49:531-7.

33. Kuntz KM, Fenwick E, Briggs A. Appropriate cohorts for cost-effectiveness analysis: to mix or not to mix? Med Decis Making. 2010;30:424-5.

34. Dewilde $\mathrm{S}$, Anderson R. The cost-effectiveness of screening programmes using single and multiple birth cohort simulations: a comparison using a model of cervical cancer. Med Decis Making. 2004;24:486-92.

35. Maynard A. Public health and economics: a marriage of necessity. J Public Health Res. 2012;1:11-3.

36. Baeten SA, Baltussen RM, Uyl-de Groot CA, Bridges JF, Niessen LW. Reducing disparities in breast cancer survival-the effect of large-scale screening of the uninsured. Breast J. 2011;17:548-9.

37. Pacelli B, Carretta E, Spadea T, Caranci N, Di Felice E, Stivanello E, et al. Does breast cancer screening level health inequalities out? A population-based study in an Italian region. Eur J Public Health. 2014;24:280-5.

\section{Submit your next manuscript to BioMed Central and we will help you at every step:}

- We accept pre-submission inquiries

- Our selector tool helps you to find the most relevant journal

- We provide round the clock customer support

- Convenient online submission

- Thorough peer review

- Inclusion in PubMed and all major indexing services

- Maximum visibility for your research

Submit your manuscript at www.biomedcentral.com/submit
) Biomed Central 